\title{
Quality characteristics of plasma treated polyester fabric
}

\author{
ARCHANA BAHUGUNA AND SHAILAJA D. NAIK
}

Received: 28.06.2017; Revised: 16.09.2017; Accepted: 02.10.2017

See end of the paper for authors' affiliations ARCHANA BAHUGUNA Department of Textile and Apparel Designing, College of Rural Home Science, University of Agricultural Sciences, DHARWAD (KARNATAKA) INDIA

Email : archana5337bahuguna@ gmail.com
ABSTRACT : Polyester is the hydrophobic synthetic fibre which lacks surface reactivity thus, leads to accumulation of electrostatic charge and poor fabric comfort. This undesirable property can be overcome through transforming the polyester into hydrophilic by modifying the surface topography. Oxygen plasma is the dry, eco-friendly finishing technique and effective means to alter the surface morphology of fibre in order to induce hydrophilicity in polyester by adding more numbers of polar groups. Surface structure was assessed by SEM (Scanning Electron Microscope) and the wettability studied by wicking action. The changes in structural, performance, durable properties after plasma treatment and on subsequent washes were basically due to etching action of plasma.

KEY WORDS: Hydrophilicity, Hydrophobicity, Oxygen plasma treatment, Polyester, Surface topography

- HOW TO CITE THIS PAPER : Bahuguna, Archana and Naik, Shailaja D. (2017). Quality characteristics of plasma treated polyester fabric. Asian J. Home Sci., 12 (2) : 328-333, DOI: 10.15740/HAS/AJHS/12.2/ 328-333. 